NASA Technical Memorandum 86380

NASA-TM-86380 19850013379

\title{
EXPLORATORY FLUTTER TEST IN A CRYOGENIC WIND TUNNEL
}

STANLEY R, COLE

FEBRUARY 1985

\section{N/Sก}

National Aeronautics and Space Administration Hampton, Virginia 23665

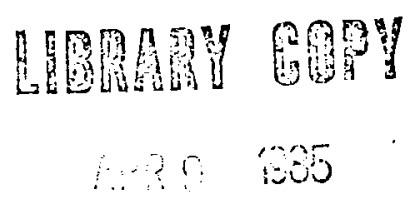

LANELEY RESEARCH CENTEE LIERRERY, NASA HANTCN, VIRGINIA 
EXPLORATORY FLUTTER TEST IN A CRYOGENIC WIND TUNHEL

Stanley R. Cole

NASA Langley Research Center

Hampton, VA 23665

\section{Abstract}

An experimental study to explore the feasibility of conducting flutter tests in cryogenic wind tunnels was conducted in the NASA LaRC 0.3-m Transonic Cryogenic Tunnel (TCT). The model used consisted of a rigid wing with an integral, flexible beam support that was cantilever mounted from the tunnel wall. The wing had a rectangular planform of aspect ratio 1.5 and a 644010 airfoll. Various considerations and procedures for conducting flutter tests in a cryogenic wind tunnel were evaluated. Flutter onset conditions were established from extrapolated subcritical response measurements. A flutter boundary was determined at cryogenic temperatures over a Mach number $M$ range from 0.5 to 0.9 . Flutter was obtained at two different Reynolds numbers $R$ at $M=0.5\left(R=4.4\right.$ and $\left.18.4 \times 10^{6}\right)$ and at $M=0.8$ $\left(R=5.0\right.$ and $\left.10.4 \times 10^{6}\right)$. Flutter analyses using subsonic lifting surface (kernel function) aerodynamics were made over the range of test conditions. To evaluate the Reynolds number effects at $M=0.5$ and 0.8 , the experimental results were adjusted using analytical trends to account for differences in the model test temperatures and mass ratios. The adjusted experimental results indicated that increasing Reynolds number from 5.0 to $20.0 \times 10^{6}$ decreased the dynamic pressure by 4.0 to 6.5 percent at $M=0.5$ and 0.8 . The Reynolds number effects may possibly be within the scatter band of the experimental measurements.

\section{Nomenclature}

A response amplitude of subcritical

response data peak, $V$

b wing semi-span, in

bo half-chord length, in

$E$ Young's modulus of elasticity, $1 b / i n^{2}$

$f$ frequency, $\mathrm{Hz}$

$f_{F} \quad$ flutter frequency, $\mathrm{Hz}$

g structural damping

9o incremental damping

$M$ Mach number

Mo model mass excluding support shaft, $1 \mathrm{~b} \cdot \mathrm{sec}^{2}$ /in

$P_{t} \quad$ stannation pressure, $i b / i^{2}$

af flutter dynamic pressure, $1 \mathrm{~h} / \mathrm{in}^{2}$

$R$ Reynolds number based on chord

$T$ temperature, ${ }^{\circ} \mathrm{F}$

$T_{t} \quad$ stagnation temperature, ${ }^{\circ} \mathrm{F}$ or $\mathrm{R}$

$v$ velocity, in/sec

$V_{F} \quad$ flutter velocity, in/sec

$v_{I} \quad$ flutter speed index $=V /\left(\omega_{0} b_{0} \sqrt{\mu}\right)$

$\rho$ density, $1 \mathrm{~b} \cdot \mathrm{sec}^{2} / \mathrm{in}^{4}$

is mass ratio $=M_{0} /\left(\pi b_{0}{ }^{2} b_{\rho}\right)$

$\mu_{c}$ coefficient of viscosity, $1 \mathrm{~b} \cdot \mathrm{sec} / \mathrm{in}^{2}$

$\checkmark$ Poisson's ratio

$\omega_{0} \quad$ first torsion frequency, radians/sec
Subscripts:

$\begin{array}{ll}\text { a } & \text { analysis result } \\ \mathrm{m} & \text { measured result } \\ i & \text { vibration mode order, } i=1,2,3, \ldots\end{array}$

\section{Introduction}

A workshop was held at the NASA Langley Research Center (LaRC) in 1980 to examine the state of technology in high Reynolds number research. Seven technical panels were assembled at the workshop to plan initial research efforts for the National Transonic Facility (NTF), a cryogenic wind tunnel which is capable of obtaining high Reynolds numbers. One of the studies recommended by the Panel on Aeroelasticity and Unsteady Aerodynamics was an exploratory flutter test of a generic wing model to determine the magnitude of possible Reynolds number effects on flutter. As a result of this panel recommendation the present flutter study was initiated. In this study, an exploratory flutter test was conducted in the 0.3-m Transonic Cryogenic Tunnel (TCT) at the NASA LaRC. The primary objectives of this test were to explore the feasibility of conducting flutter tests in a cryogenic wind tunnel and to develop procedures for such test.s. Another objective was to determine if Reynolds number effects could be separated from the effects of other test parameters which are known to influence flutter and, if so, how significant is the effect of Reynolds number on classical wing flutter (bending-torsion coupling).

The approach used in this study was to design a flutter model that would be both simple to analyze and reasonably safe to test in a cryogenic wind tunnel. A reliable analytical prediction of the flutter boundary was important so that actual, "hard" flutter could be avoided during the test or, at least, approached cautiously. Even so, this test was approached as a high-risk test in the 0.3-m TCT. The present flutter model design consists of a relatively rigid wing mounted on a short integral, rectangular beam flexure, the root of which is clamped to the tunnel wail. The wing was constructed of solid metal with a symmetric airfoil section. The wing planform was rectangular and had a panel aspect ratio of 1.5. The flexure beam was sized to give primary wing bending and torsion frequencles that would permit the wing to flutter at the desired dynamic pressure in the tunnel. With this design, the analysis was simplified because the majority of the flexiblifty is exhibited in the rectangular beam support while the aerodynamic forces are generated by the "rigid" wing.

Several special considerations are needed for aeroelastic model testing in a cryogenic wind tunnel. In order to utilize its full Reynolds number and dynamic pressure capabilities, the large temperature range capability of a cryogenic facility must be 
exercised and this causes many changes not normally experienced in conventional wind tunnels. For this reason, ground vibration tests (GVT) were conducted on this cryogenic flutter model throughout the operating temperature range of the $0.3-m$ TCT before beginning the wind-tunnel test. Results from the GVT were used in the flutter analysis.

In cryogenic tunnels there are several different operating procedures for approaching the flutter boundary. During the present wind-tunnel test, two tunnel operating procedures were evaluated. The four test parameters which were considered to have the most significant effects on flutter were temperature (because temperature affects vibration frequencies), mass ratio, Mach number, and Reynolds number. An attempt was made to isolate any Reynolds number effect on flutter by using appropriate test procedures and by using analytical trends to adjust experimental results obtained at a constant Mach number. Presented herein are the results of this study.

\section{Test Apparatus}

Wind Tunnel

The $0.3-m \mathrm{TCT}^{2}$ is a closed circuit, continuous wind tunnel that provides the capability of testing at high Reynolds number by a combination of low temperature and high pressure. The cryogenic temperatures are obtained by injecting liquid nitrogen $\left(-320^{\circ} \mathrm{F}\right)$ into the tunnel circuit. The liquid evaporates and the tests are conducted in gaseous nitrogen. The pressure in the tunnel can be varied from about one to six atmospheres. The effects of cryogenic temperatures on Reynolds number and other test parameters are shown in Fig. $1^{3}$. Note that the changes shown are for a constant model size, pressure, and Mach number. Reynolds number is defined as:

$$
R=\frac{\text { Inertia force }}{\text { Viscous force }}=\frac{\rho V^{2}\left(2 b_{0}\right)^{2}}{\mu_{c} V\left(2 b_{0}\right)}=\frac{\rho V\left(2 b_{0}\right)}{\mu_{c}}
$$

Based on these relationships (Fig. 1), the net result of lowering the test medium temperature is to cause a large increase in Reynolds number. Also, note that the dynamic pressure is independent of temperature. Therefore, tests can be conducted at high Reynolds numbers with modest dynamic pressures (as compared to an ambient temperature pressure tunnell, and aiso, Reynolds number may be varied while holding the dynamic pressure constant. Furthermore, aeroelastic testing can be conducted at a constant Reynolds number by proper control of pressure and temperature (Fig. 2).

\section{Wind-Tunnel Model}

The cryogenic wind-tunnel model design consists of a rectangular planform wing supported by an integral, rectangular beam flexure. The beam flexure was clamped to the wind-tunnel turntable. Photographs of the nodel and sketches giving geometric information are presented in Figs. 3 and 4 , respectively. The wing has an aspect ratio of 1.5 and a NACA $64 A 010$ airfoil shape. A semi-circular wing tip shape with a diameter equal to the thickness of the wing at a given chord station was used. Also, a circular plate was attached to the wing root as a cover over the support flexure slot in the turntable (see Fig. 3). The flexure is attached to the wing root at the 0.3 -chord position (Fig. 4).

Model material.- Cryogenic temperatures eliminate the use of some conventional construction materials because of undesirable characteristics at low temperatures. An $18 \mathrm{Ni}$ grade 200 maraging. steel was chosen as the material for the present flutter model because of its high strength and relatively constant properties over a large temperature range. Figure $5^{4,5}$ shows that the Young's modulus of elasticity $(E)$ varies less than 5 percent and Poisson's ratio $(v)$ varies less than 2 percent over the temperature operating range of the $0.3-\mathrm{m}$ TCT. Also, the dimensional stability of $18 \mathrm{Ni}$ grade 200 steel with temperature makes it a highly desirable material for transonic airfoils which require extremely close tolerances. An additional advantage of this steel alloy is its high fracture toughness. A flutter model, which is designed primarily by stiffness criteria rather than strength, becomes safer to test when high strength and high ductility materials can be used. One undesirable characteristic of high strength alloys is that the material may fail in a brittle manner if cracks are present even though the tensile ductility of the material is high". This is a condition that must he avoided in a flutter model because of the possibility of a brittle fracture occurring as the model undergoes oscillations normally encountered during flutter testing. No "hard" flutter points were obtained during this test in an effort to minimize the risk of such a failure. The high strength and fracture toughness values of $18 \mathrm{Ni}$ grade 200 steel also decreased the probability of fallure.

Instrumentation.- The model was
instrumented with two strain gage bridges
located on the support flexure near the
cantilever point and oriented respectively such
that the bending and torsional strains were
measured. A thermocouple was mounted near the
strain gage bridges for monitoring the
temperature of the model. This temperature
measurement was intended to be used to correct
for thermal drift of the strain gage bridge
sensitivity. The sensitivity of the strain gage
bridges used for this test, however, varied by
less than one percent over the temperature range
tested so no corrections were considered
necessary. The thermocouple on the model was
used to indicate when the temperature of the
support flexure reached equilibrium with time.

\section{Model Mounting System}

The test section used for the present test in the $0.3-m$ TCT was eight inches wide which limits sidewall-mounted, three-dimensional models to a maximum semi-span of approximately five inches. A support system was designed for the flutter model which allowed the support flexure to extend through a rectangular slot in the sidewall turntable so that the tunnel width was better utflized. Two blocks were 
constructed from $18 \mathrm{NI}$ arade 200 maraging steel which clamp above and below the support flexure as shown in Fia. 4. The morel is allaned hy steel pins and clamped by four screws that pull the blocks tight around the support flexure of the model. These blocks are then attached to the back side of the aluminum turntable by three screws.

As a special safety feature, four cylindrical shaped teflon pads were mounted inside the turntable slot near the wing root as shown in Fla. 4. These pads were designed to limit the amplitude of deflection of the model and to soften the impact anainst the flexure if flutter occurred during the test. The gap between the teflon pads and the support flexure was sized by the ultimate strength of the model support flexure material.

During testing, the model was constantly monitored by television through a video camera and a visual record was taped for later review. A movie camera was activated manually only when something of interest occurred.

\section{Test Procedures}

\section{Ground Vibration Test}

A ground vihration test (GVT) was conducted on the cryogenic flutter model at temperatures throughout the operating range of the $0.3-m$ TCT. A cryogenic chamber facility that uses liquid nitronen to obtain the low temperature environment was used for the GVT. The flutter model/turntahle assembly was mounted to an aluminum hackstop in this cryogenic chamber. Excitation was provided in the enclosed facility by manually plucking the model with a wooden rod extending through a hole in the bottom of the chamber. The model could he excited usually in either the first bending or the first torsion mode in this manner. These are the two modes primarily involved in the flutter phenomena for this model. Natural frenuencies and structural damping were measured for each of these modes. The natural frequencles were obtained from the strain gage bridge responses as monitored by a dynamic signal analyzer. The damping was measured by strain-gage signal decay envelopes monitored on a strip chart recorder. The generalized masses and the natural mode shapes for these two modes were also measured at room temperature. This verifled the analytical structural dynamic simulations that were used in the flutter analysis. The measured natural frequencles are shown in Table 1 and in Fig. 6 . The measured structural damping values are shown in Fig. 7 and measured node lines are shown in Fig. 8. Calculated frequencles and node lines are included in Fig. 8.

\section{Wind-Tunnel Test}

Conventionally, flutter tests are conducted by slowly increasing dynamic pressure until the flutter critical condition is predicted by subcritical response techniques, or until flutter actually occurs. Because the goal in cryogenic testing is to determine Reynolds number effects, operating procedures for conducting flutter tests must allow control of both Reynolds number and dynamic pressure. The 0.3-m TCT allows independent control of Mach number, temperature, and pressure. Reynolds number is indirectiy controlled by proper variation of at least two of these three tunnel conditions. Many combinations of changes in these tunnel parameters can be used to approach a flutter condition. The two tunnel operating procedures that were considered most suitable for flutter model testing were selected for and evaluated in the present test. These procedures are discussed in the following paragraphs.

1) Constant Mach number and Reynolds Number.- This tunnel operating procedure and the resulting variations in the flow parameters are shown in Fig. 9 as procedure number 1 . Testing at constant Mach number has the advantage of being a relatively safe method of flutter testing. Holding Reynolds number constant eliminates its possible effects on the aerodynamics and experimental flutter predictions. A disadvantage is that monitoring the necessary changes in stagnation temperature and pressure to keep the Reynolds number constant can become a major task to the project engineer whose major concern is monitoring the model's behavior. This operating procedure is also rather slow because of the changes that must be made to keep Reynolds number constant, nevertheless it can be used very successfully. However, the changing material properties with temperature may make this procedure undesirable for flutter testing in some instances.

2) Constant Mach Number and Stagnation Temperature.- This tunnel operating procedure is shown as procedure 2 in Fig. 9. Here the tunnel operation is relatively easy because only stagnation pressure must be changed to approach the flutter instability. Because the temperature is held constant, the material properties of the model do not vary during testing. A less desirable consequence is that the Reynolds number is changing as the stagnation pressure is increased. The direct approach to the fiutter boundary makes this a relatively safe, and probably the best, procedure for conducting flutter tests. This procedure was used to obtain most of the experimental flutter conditions during this test.

\section{Subcritical Response Technique}

A subcritical response technique, known as the Peak-Hold method ${ }^{6}$, was used to predict the onset of flutter during this test. This method involves measuring the maximum response amplitude of a vibration mode for a specific time period and at a constant dynamic pressure. This measurement is repeated as the dynamic pressure is incrementally increased. Both strain gage bridge outputs were mont tored by the Peak-Hold method during this test, but the response from the torsion gage gave the most consistent predictions of flutter onset. Some typical measured subcritical response spectra are shown in Fig. 10. At low dynamic pressures, the peaks corresponding to the natural vibration modes are relatively broad which suggests that the modes are either well damped or simply not excited by the tunnel turbulence. At conditions near flutter, the response should appear as a distinct, narrow 
peak indicative of low modal damping. Such "Ideal" response data were not generally obtained during this test, hut the Peak-Hold method still aave consistent trends and flutter onset predictions. The response data shown in Fig. 10 at the maximum test dynamic pressure is within 91 percent of the predicted flutter dynamic pressure for hoth cases. Although narrow peaks were not obtained, maximum wide-hand responses did occur near frenuencles corresponding to the first bending and the first torsion modes. In the Peak-Hold method, the inverse of the maximum response amplitude is plotted versus dynamic pressure as each measurement is made. As the flutter dynamic pressure is approached, the response amplitude grows infinitely large--at least relative to the response amplitudes at the lower dynamic pressures, so that when the reciprocal of the response is extrapolated to a zero value, the corresponding dynamic pressure required for flutter is estabilished. This can be seen in the Peak-Hold method plots (Fig. 11) obtained in this test.

The subcritical response measurements (Fig. 10) show another interesting phenomenon. Fig. $10(a)$ and $10(b)$, respectively, are response measurements at $M=0.5$ for ambient temperature $\left(T_{t}=80.6^{\circ} \mathrm{F}\right)$ and for a cryogenic temperature $\left(T_{t}=-261.4^{\circ} \mathrm{F}\right)$. The temperature level is the major difference between these two measurements. The data were measured on the same day, with the same equipment setup, during consecutive wind-tunnel runs. Yet the response measurement trends are very different for conditions that are the same percentage removed from the predicted flutter dynamic pressure. The measurements at $T_{t}=80.6^{\circ} \mathrm{F}$ indicate greater model response amplitude and lower damping (more distinct response peaks) than the ineasurements at $T_{t}=-261.4^{\circ} \mathrm{F}$. This difference in model response is probably due to the reduced power requirement to operate the tunnel at the lower temperature as shown in Fig. 1. At reduced power, less energy is being input into the tunnel flow and consequently, there is probably less turbulence to excite the model.

\section{Analytical Predictions}

Analyses were conducted for the cryogentc model to predict the flutter conditions as a guide for the wind-tunnel test and to separate the effects of Reynolds number on flutter from the effects of mass ratio and temperature changes. Structural dynamic propertles of the flutter model were calculated using the Engineering Analysis Language (EAL) finite element analysis software system ${ }^{7}$. The finite element model used two-dimensional plate elements as shown in Fig. 12. EAL was used to calculate natural mode shapes, natural frequencles, and generalized masses for the flutter model (Table 1 and Figs. 6 and 8 ). These analytical results were compared to characteristics obtained in the GVT for the flutter model. Flutter analysis was then conducted using experimentally determined properties or calculated properties if measured values were not avallable. A flutter analysis software system, known as FAST $^{8}$, was used to calculate the flutter instablifty condition. FAST calculates the flutter solution by the $k$ method using aerodynamics obtained through subsonic kernel function iffing-surface theory. A typical analysis result showing frequency and damping versus the flutter speed index is shown in Fig. 13. Flutter results were obtained for $M=0.5,0.7,0.8,0.85$, and 0.9 and are presented in Table 2.

\section{Mass Ratio Effects}

Prior to this test, it was realized that mass ratio could possibly have a strong effect on flutter because of the large variation in fluid density that occurs during cryogenic testing. Reference 9 has suggested that it is possible to conduct cryogenic flutter tests at several Reynolds numbers whlle avoiding mass ratio effects by constructing several models fron different materials. Because only one model was built for this test, analytical results were used to account for the effects of mass ratio on flutter. An example flutter analysis calculation for this model is shown in Fig. 14. This figure shows the fluid density that must be attained to induce flutter for a constant Mach number and a given velocity. (For this example, the analysis solution assumed material properties that were independent of temperature.) For a conventional wind tunnel, temperature is virtually constant so that there is a specific velocity associated with a constant Mach number and there is only one density associated with flutter as can be seen on the solution curve in the figure. The analytic flutter solution at this density and velocity are known as the "matched point" conditions. In a cryogenic wind tunnel, multiple matched point conditions are possible because of the variation in velocity due to changes in the temperature. The range of matched point conditions for the temperatures attainable in the $0.3-\mathrm{m}$ TCT is shown in Fig. 14. The velocity versus density plot was transformed into a plot of dynamic pressure versus mass ratio as shown in figure 15. It was then used to determine the percentage dynamic pressure correction between the actual test mass ratio values. This was the procedure used to adjust the experimental flutter dynamic pressures for mass ratio effects. The predicted effects of mass ratio on flutter were found to be fairly small for the range of test mass ratios.

\section{Temperature Effects}

Analysis was also conducted to predict the effect of the temperature variation on flutter. Measured structural properties at the specified temperature conditions that covered the test range were used in the analysis. This analysts was conducted at a constant mass ratio corresponding to the lowest Reynolds number experimental data point. The effect of temperature on flutter as predicted by analysis can be seen in Fig. 15. As indicated in the figure, decreasing temperature results in increasing the flutter dynamic pressure. This is attributed to the increasing model stiffness reflecting the elastic moduli changes as the temperature decreases. 
Test Results and Discussion

\section{Experimental Data}

The experimental flutter results obtained in the $0.3-\mathrm{m}$ TCT test are given in Table 3 . For this flutter test, the model had free transition and was maintained at a near zero degree angle of attack in a $1 \mathrm{~g}$ lift condition, i.e., aerodynamically supporting the wing weight. Ali of the experimental flutter conditions were obtained by Peak-Hold method extrapolations using measured subcritical response data. Experimental flutter conditions were determinen for this model at $M=0.5,0.7,0.8,0.85$, and 0.9 . At $M=0.5$, flutter was obtained for Reynolds numbers of 4.4 and $18.4 \times 10^{6}$. At $M=0.8$, flutter was obtained for Reynolds numbers of 5.0 and $10.4 \times 10^{6}$. As shown in Fig. 16, the FAST analysis predicted the experimental flutter dynamic pressures rather well, with the analytical results ranging from up to 5 percent nonconservative at the lowest Mach number tested to approximately 5 percent conservative at the high Mach number test conditions. The Mach number effects on the flutter dynamic pressure also appear to be well predicted by the analysis.

\section{Reynolds Number Effects}

The effects of temperature and mass ratio variation between different prediction cases have not been removed from the experimental data of Fig. 16. In an attempt to determine the Reynolds number effects on flutter, flutter points were obtained at two different Reynolds numbers at $M=0.5$ and 0.8 . With Mach number held constant, the only other test parameters that are believed to significantly affect the flutter dynamic pressure are the differences in temperature, mass ratio, and Reynolds number. Analytical trends were used to remove the temperature effects and the mass ratio effects so that the Reynolds number hecomes the sole parametric effect. The temperature adjustment was made by offsetting the experimental results by a percentage amount equal to the percentage variation in the flutter dynamic pressure predicted by analysis from the given test temperature to the reference temperature of $80.6^{\circ} \mathrm{F}$ using the trends shown in Fig. 15. In a similar manner, the experimental data was further adjusted for the effects of mass ratio. The resulting increments are shown in Fig. 17 where the final adjusted experimental data shows the variation in flutter dynamic pressure which is attributed solely to Reynolds number effects. At $M=0.5$, the flutter dynamic pressure decreased by 3.8 percent as the Reynolds. number is increased from 4.4 to $18.4 \times 10^{6}$. At $M=0.8$, the decrease is 2.3 percent for a Reynolds number increase from 5.0 to $10.4 \times 10^{6}$. A linear extrapolation of the data at $M=0.8$ gives a 5.8 percent decrease in flutter dynamic pressure as Reynolds number is increased over the same range as at $M=0.5$ $\left(R=4.4\right.$ to $\left.18.4 \times 10^{6}\right)$. Because that no hard flutter points were obtained as an absolute verification of the flutter conditions, this effect could possibly fall within the scatter band of the subcritical response predictions which was never established in the present test. It is the author's opinion that the
Reynolds number effect shown in Fig. 17 would be reduced or eliminated by the scatter in the experimental results.

\section{Conclusions}

The feasibility of conducting flutter tests in cryogenic wind tunneis has been examined through this test. It has been found that, while high-risk flutter testing is possible in a cryogenic-tunnel, many considerations must be made that are not usual concerns for flutter tests in conventional wind tunnels. Flutter conditions were extrapolated during this test using a subcritical response technique rather than by obtaining hard flutter points. The subcritical response technique gave consistent results throughout the temperature range of the tunnel. Several tunnel operating procedures for flutter testing in a cryogenic wind tunnel were evaluated. The operating procedure that is considered best is to increase the tunnel stagnation pressure while holding Mach number and stagnation temperature constant.

The important conclusions derived from this cryogenic flutter test are:

1) For a single test model, the effects of mass ratio and temperature cannot be experimentally separated from the effects of Reynoids number on flutter. Analytical trends were used to adjust experimental results to obtain the present Reynolds number effects on flutter.

2) The experimental effects of Reynolds number on the flutter characteristics of a rectangular planform, symmetrical airfoil shaped wing are small. Increasing Reynolds number from 5.0 to $20.0 \times 10^{6}$ decreased the adjusted flutter dynamic pressure by 4.0 to 6.5 percent at $M=0.5$ and 0.8 . This small percentage decrease may possibly be within the scatter band of the experimental subcritical response predictions.

3) Temperature effects on flutter are appreciable but not large because of changes in material stiffness properties.

\section{References}

${ }^{1}$ High Reynolds Number Research - 1980. NASA Conference Publication 2183, 1980.

2Ray, Edward J.; Ladson, Charles L.; Adcock, Jerry B.; Lawing, Plerce L.; and Hall, Robert M.: Review of Design and Operational Characteristics of the 0.3-Meter Transonic Cryogenic Tunnel. NASA TM 80123, 1979.

${ }^{3}$ Kilgore, Robert A; Goodyer, Michael J.; Adcock, Jerry B.; and Davenport, Edwin E.: The Cryogenic Wind-Tunnel Concept for High Reynolds Number Testing. NASA TN-D-7762, 1974.

${ }^{4}$ Tobler, R. L.: Materials for Cryogenic Wind Tunnel Testing. NBSIR 79-1624, 1980.

'Young, Clarence P., Jr.; Bradshaw, James R.; Rush, Homer F., Jr.; Wallace, John W.; and Watkins, Vernon E., Jr.: Cryogenic Wind-Tunnel 
Model Technology Development Activities at the NASA Langley Research Center. AlAA-84-0586, 1984 .

${ }^{6}$ Sandford, Maynard C.; Abel, Irving; and Gray, David L.: Development and Demonstration of a Flutter-Suppression System Using Active Controls. NASA TR-R-450, 1975.

${ }^{7}$ Whetstone, W. D.: EISI-EAL Englneering Analysis Language Reference Manual. Engineering Information Systems, Inc., 1983.

${ }^{8}$ Desmarais, Robert $\mathrm{N} . ;_{\text {; }}$ and Bennett, Robert M.: User's Gulde for a Modular Flutter Analysis Software System (FAST Version 1.0). NASA TM-78720, 1978.

${ }^{9}$ Hanson, Perry W.: An Assessment of the Future Roles of the National Transonic Facility and the Langley Transonic Dynamics Tunnel in Aeroelastic and Unsteady Aerodynamic Testing. NASA TM 81839, 1980.

Table 1.-Calculated and measured natural frequencies at various model temperatures.

\begin{tabular}{|c|c|c|c|c|c|c|c|c|}
\hline \multirow[b]{2}{*}{ MODE } & \multicolumn{4}{|c|}{$T=-261 .{ }^{\circ} \mathrm{F} \mid T=-252 .^{\circ} \mathrm{F}$} & \multicolumn{4}{|c|}{ 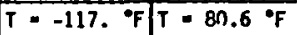 } \\
\hline & $\begin{array}{l}f_{a}, \\
\mathrm{~Hz}\end{array}$ & $\begin{array}{l}f_{m_{1}} \\
H_{z}\end{array}$ & $\mathrm{f}_{\mathbf{a}}$ & $\begin{array}{l}f_{m}, \\
\mathrm{~Hz}\end{array}$ & $\mathrm{f}_{\mathrm{dz}}$ & $\begin{array}{l}P_{m} \\
H_{2}\end{array}$ & $f_{\mathbf{B}}$, & ${ }_{\mathrm{Hz}}^{\mathrm{t}}$ \\
\hline 1-FIrst & 16.4 & 16.6 & 16.3 & 16.6 & 16.2 & 16.4 & 16.0 & 16.1 \\
\hline 2-chord & 94.6 & -- & 94.6 & -- & 93.8 & $\cdots$ & 92.6 & 89.0 \\
\hline 3-First & 103.7 & 102.3 & 103.6 & 102.3 & 102.7 & $\mid 101.6$ & 101.4 & 99.5 \\
\hline 4-Second & 293.5 & -- & 293.2 & 296. & 290.9 & -- & 287.4 & 284. \\
\hline $\begin{array}{l}\text { 5-Third } \\
\text { bending }\end{array}$ & 1359. & -- & 1358. & -- & 1347. & -- & 1330. & -- \\
\hline
\end{tabular}

Table 2.-Calculated model flutter results

\begin{tabular}{|c|c|c|c|c|c|c|c|}
\hline M & $\begin{array}{l}T_{t}, \\
{ }^{\prime}\end{array}$ & $\begin{array}{l}V_{F} \\
\text { inisec }\end{array}$ & ${ }^{a_{F}},{ }_{1} / n^{2}$ & $v_{1}$ & $\begin{array}{l}f_{F}, \\
H z\end{array}$ & $\mu$ & $\begin{array}{l}\rho \times 10^{6} \\
1 b \cdot \sec ^{2} / \ln { }^{4}\end{array}$ \\
\hline .5 & $\begin{array}{l}-261 . \\
-252 . \\
-117 . \\
80.6\end{array}$ & $\begin{array}{l}3912 \\
4027 \\
5357 \\
6780\end{array}$ & $\begin{array}{l}13.72 \\
13.69 \\
13.23 \\
12.56\end{array}$ & $\begin{array}{l}.67 \\
.67 \\
.66 \\
.66\end{array}$ & {$\left[\begin{array}{l}46.7 \\
46.7 \\
46.3 \\
45.2\end{array}\right]$} & $\begin{array}{r}36.7 \\
38.9 \\
71.7 \\
121.0\end{array}$ & $\begin{array}{c}1.79 \\
1.69 \\
.922 \\
.546\end{array}$ \\
\hline .7 & $\begin{array}{r}-261 . \\
-252 . \\
-117 . \\
80.6\end{array}$ & $\begin{array}{l}5477 \\
5626 \\
7361 \\
9285\end{array}$ & $\begin{array}{l}12.47 \\
12.46 \\
12.16 \\
11.59\end{array}$ & $\begin{array}{l}.64 \\
.64 \\
.62 \\
.61\end{array}$ & $\mid \begin{array}{l}41.6 \\
41.6 \\
41.1 \\
40.2\end{array}$ & $\begin{array}{r}79.4 \\
84.0 \\
147.2 \\
245.7\end{array}$ & $\begin{array}{l}.832 \\
.787 \\
.449 \\
.269\end{array}$ \\
\hline .8 & $\begin{array}{r}-261 . \\
-252 . \\
-117 . \\
80.6\end{array}$ & $\begin{array}{r}6215 \\
6371 \\
8306 \\
10470\end{array}$ & $\begin{array}{l}11.53 \\
11.53 \\
11.26 \\
10.75\end{array}$ & $\begin{array}{l}.61 \\
.61 \\
.60 \\
.59\end{array}$ & $\begin{array}{l}37.7 \\
37.7 \\
37.4 \\
36.6\end{array}$ & $\begin{array}{l}110.7 \\
116.3 \\
202.7 \\
337.2\end{array}$ & $\begin{array}{l}.597 \\
.568 \\
.326 \\
.196\end{array}$ \\
\hline .85 & $\left|\begin{array}{r|}-261 . \\
-252 . \\
-117 . \\
80.6\end{array}\right|$ & $\begin{array}{r}6570 \\
6734 \\
8764 \\
11045\end{array}$ & $\begin{array}{l}10.87 \\
10.86 \\
10.62 \\
10.15\end{array}$ & $\begin{array}{l}.60 \\
.60 \\
.58 \\
.58\end{array}$ & $\mid \begin{array}{l}35.3 \\
35.3 \\
35.0 \\
34.2\end{array}$ & $\begin{array}{l}131.4 \\
138.0 \\
238.6 \\
398.1\end{array}$ & $\begin{array}{l}.503 \\
.479 \\
.277 \\
.166\end{array}$ \\
\hline .9 & $\begin{array}{r}-261 . \\
-252 . \\
-117 . \\
80.6\end{array}$ & $\begin{array}{r}6923 \\
7093 \\
9214 \\
11606\end{array}$ & $\begin{array}{l}9.96 \\
9.96 \\
9.74 \\
9.31\end{array}$ & $\begin{array}{l}.58 \\
.58 \\
.57 \\
.58\end{array}$ & $\left|\begin{array}{l}32.3 \\
32.3 \\
32.0 \\
31.4\end{array}\right|$ & $\begin{array}{l}158.9 \\
166.9 \\
288.6 \\
478.9\end{array}$ & $\begin{array}{l}.416 \\
.395 \\
.229 \\
.138\end{array}$ \\
\hline
\end{tabular}

Table 3.-Experimental flutter results.

\begin{tabular}{|c|c|c|c|c|c|c|c|c|}
\hline M & $r_{t}$, & $\mid \begin{array}{l}V_{F} \\
\text { inisec }\end{array}$ & $\begin{array}{l}7_{F} \\
1 b / i n^{2}\end{array}$ & $v_{1}$ & $\mid \begin{array}{l}\mathrm{F}_{\mathrm{F}} \\
\mathrm{Hz}\end{array}$ & $\mu$ & $\begin{array}{c}\rho \times 10^{6} \\
1 b \cdot \sec ^{2} / 1 n^{4}\end{array}$ & $R \times 10^{-6}$ \\
\hline $\begin{array}{l}.5 \\
.5\end{array}$ & $\begin{array}{r}-261 . \\
80.6\end{array}$ & $\begin{array}{l}3911 . \\
6780 .\end{array}$ & $\mid \begin{array}{l}12.95 \\
12.35\end{array}$ & $\begin{array}{l}.65 \\
.66\end{array}$ & $\begin{array}{l}49 . \\
47 .\end{array}$ & $\begin{array}{r}38.7 \\
119.0\end{array} \mid$ & $\begin{array}{c}1.67 \\
.545\end{array}$ & $\begin{array}{c}18.16 \\
4.38\end{array}$ \\
\hline .7 & -117 & 7360. & 11.60 & .63 & 40. & $\mid 149.4$ & .434 & 5.77 \\
\hline .8 & $\begin{array}{l}-252 \\
-117\end{array}$ & $\begin{array}{l}6372 . \\
8306 .\end{array}$ & $\begin{array}{l}11.23 \\
11.23\end{array}$ & $\begin{array}{l}.61 \\
.62\end{array}$ & 33. & $\left|\begin{array}{l}116.6 \\
198.1\end{array}\right|$ & $\begin{array}{l}.556 \\
.327\end{array}$ & $\begin{array}{r}10.41 \\
5.04\end{array}$ \\
\hline .85 & -117. & 8765. & 10.80 & .60 & 37. & 229.6 & .282 & 4.66 \\
\hline .9 & -117 & 9214. & 10.00 & .58 & 27. & 279.2 & .232 & 4.09 \\
\hline
\end{tabular}

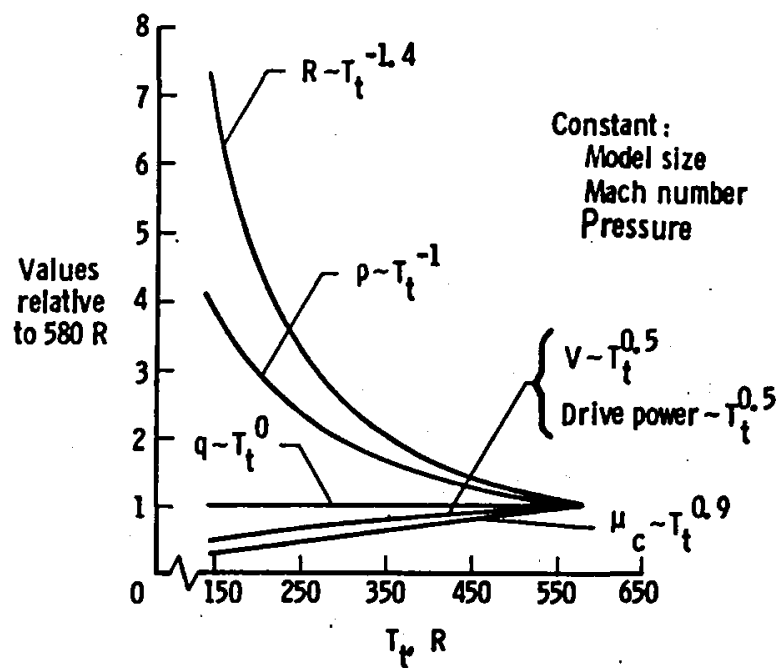

Fig. 1 Temperature variation of tunnel parameters.

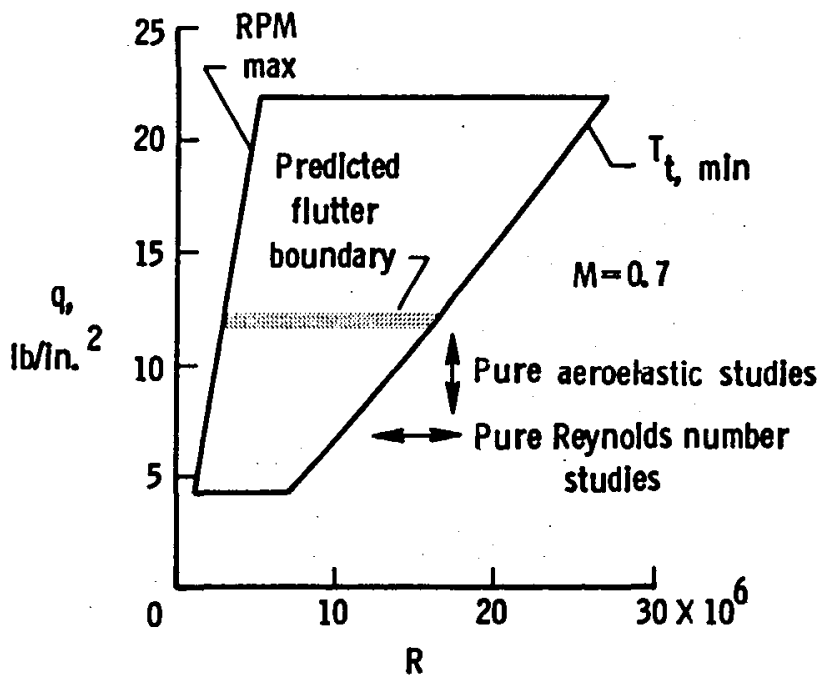

Fig. 2 Operating boundary for the $0.3-m$ TCT showing two types of experimental studies. 


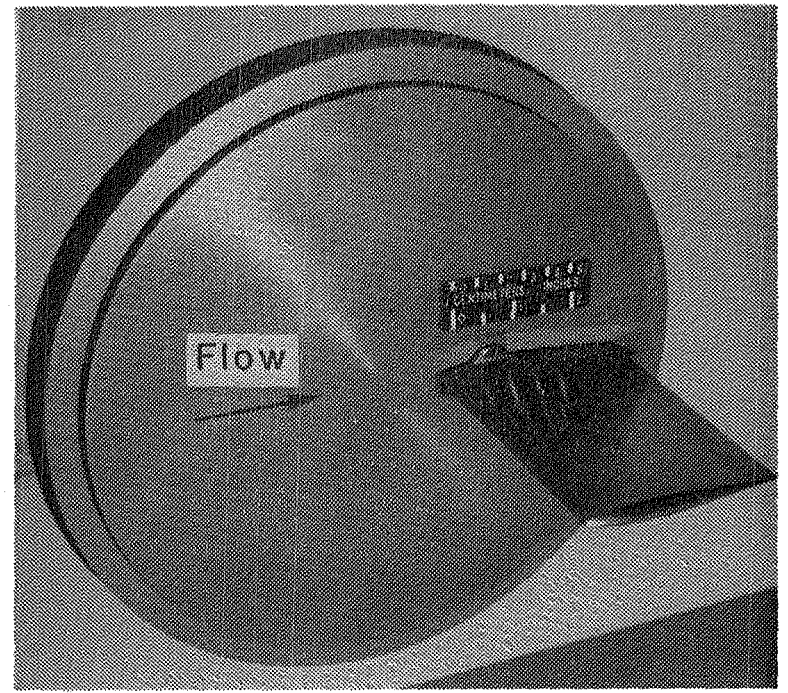

(a) Three-quarter side view

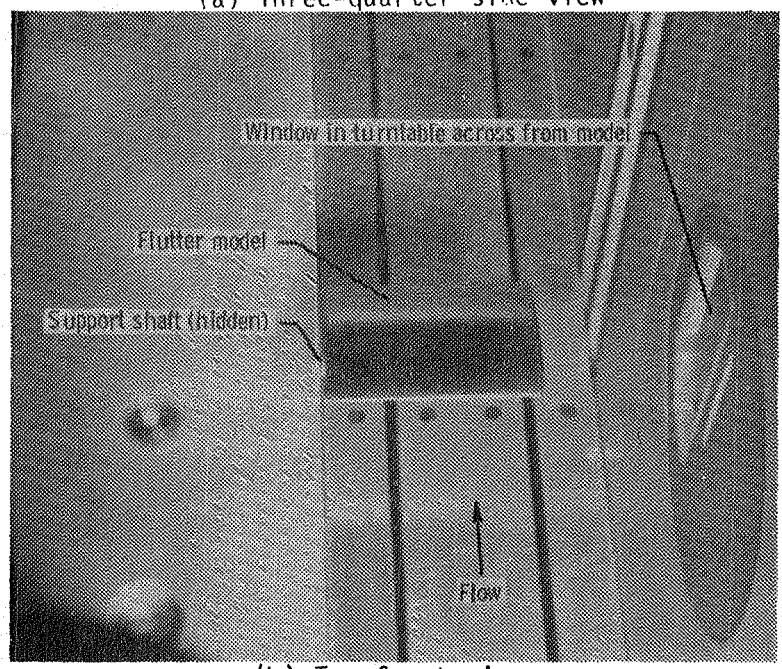

(b) Top-front view

Fig. 3 Photographs of model mounted in tunnel.

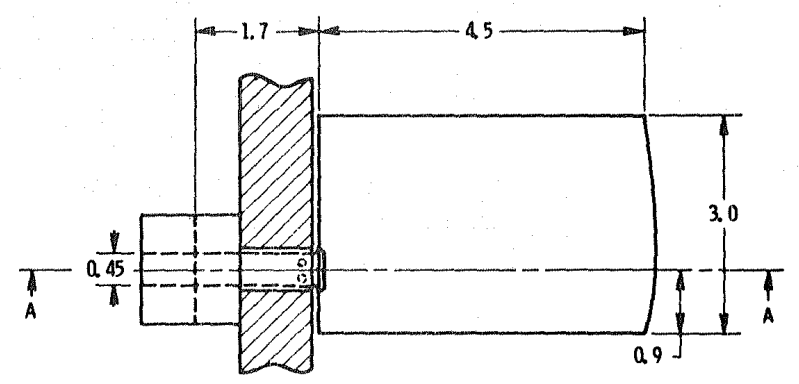

Top view

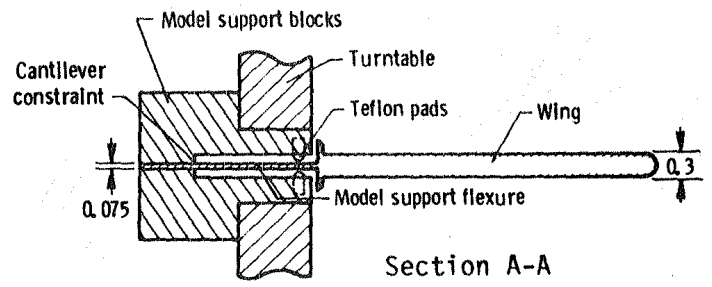

Fig. 4 Sketches of model and support arrangement. (Dimensions are inches.)

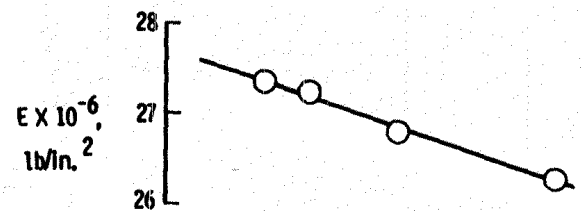

(a) Young's modulus

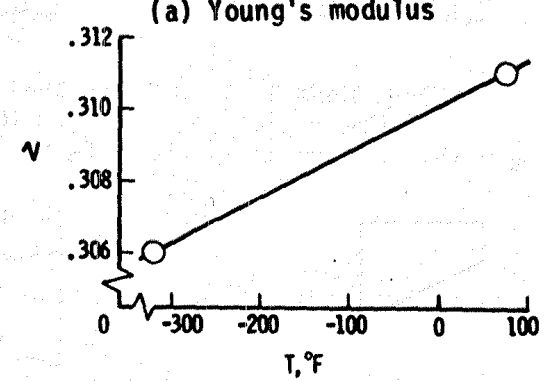

(b) Polsson's ratio

Fig. 5 Temperature variation of some properties of $18 \mathrm{Ni}$ grade 200 steel.
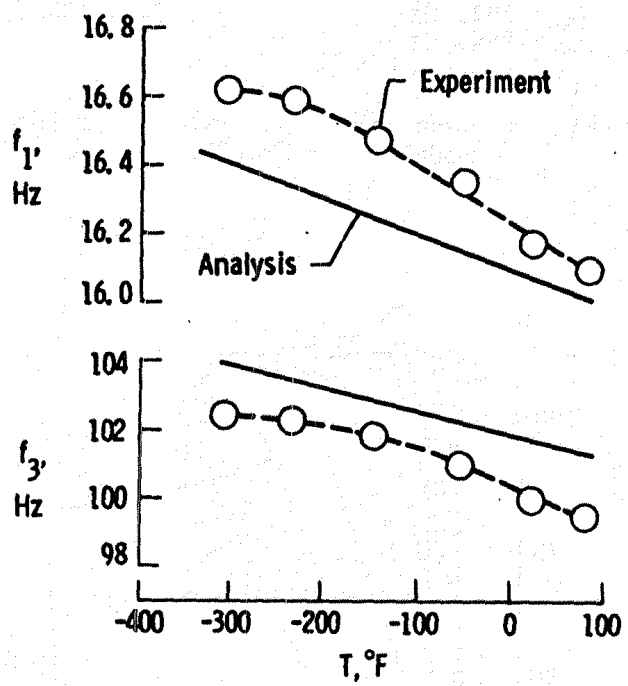

Fia. 6 Some measured and calculated frequencies.
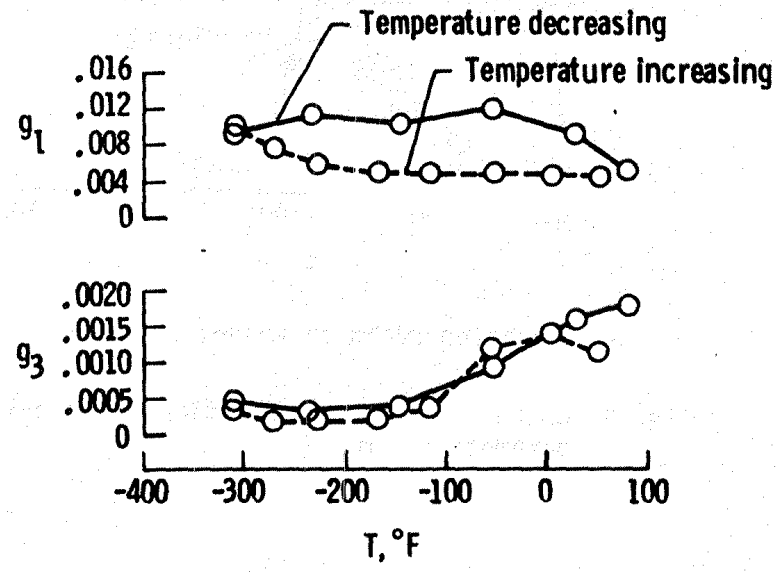

Fig. 7 Measured structural damping values. 


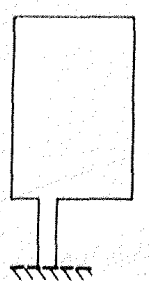

First bending, Mode 1

$f_{z}=16.0 \mathrm{~Hz}$

$f_{m}=16.1 \mathrm{~Hz}$

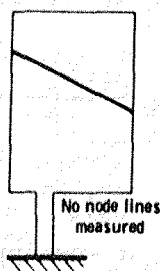

Second bending, Mode 4 $f_{a}=287 . H z$

Flg. 8 Node 1 Ines and frequencles for the model. $T=80.6^{\circ} \mathrm{F}$.

25.

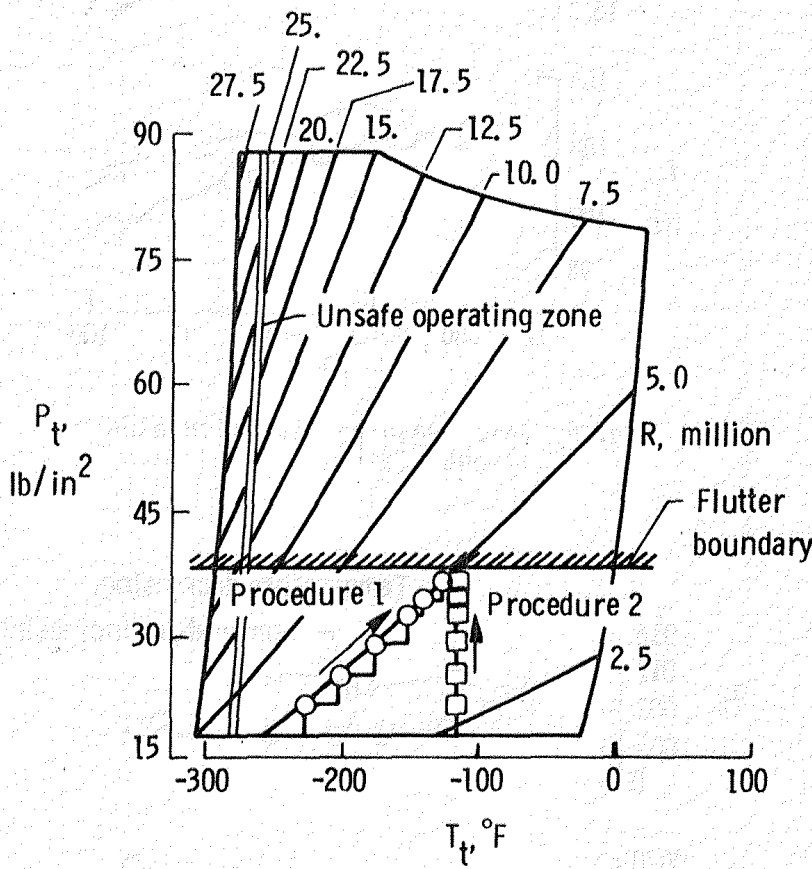

(a) Operating paths on tunnel boundary.

FIg. 9 Operating paths as function of tunnel parameters. $M=0.8$.
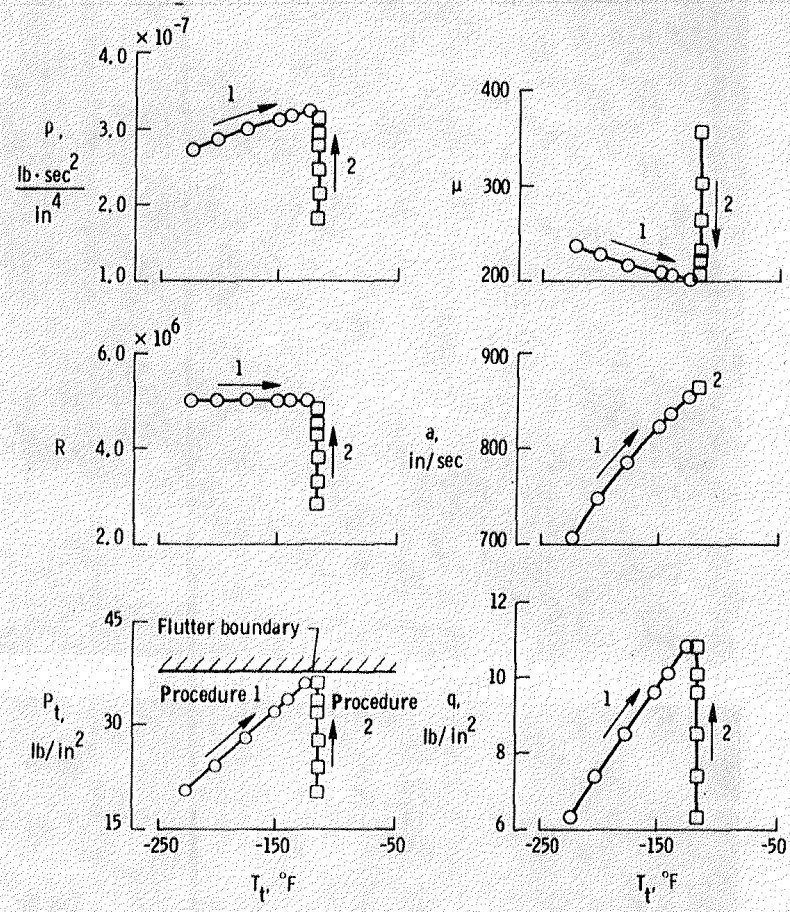

Fla. 9 (b) Variation of tunnel parameters.
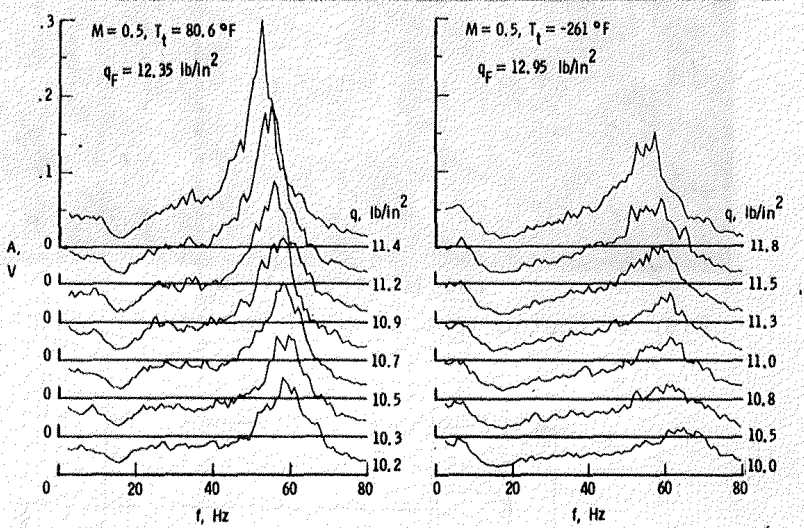

Flg. 10 Typical subcritical response measurement data.
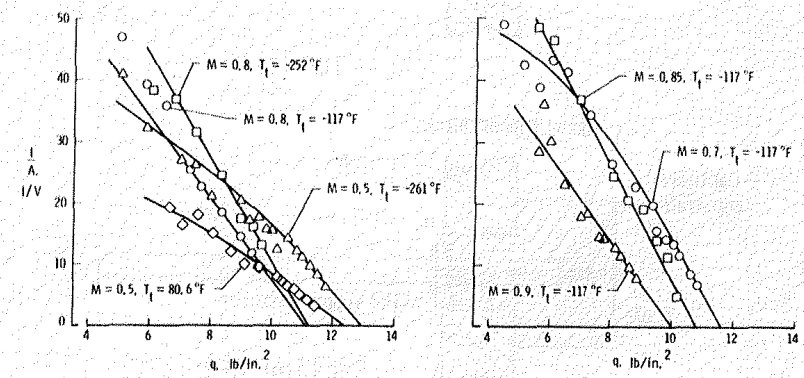

Fig. 11 Test Peak-Hold plots. 


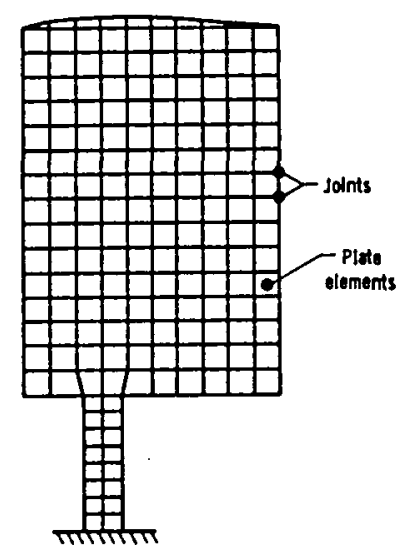

Fig. 12 Finite element simulation of model.
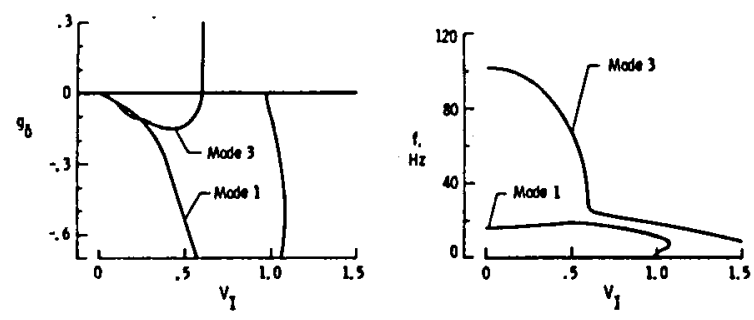

Fig. 13 Typical calculated flutter results.

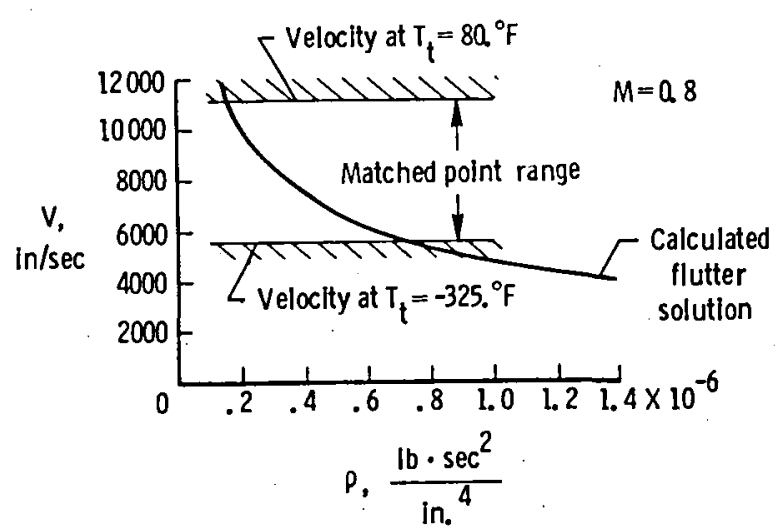

Fig. 14 Calculated flutter solution showing the matched point range in the $0.3-\mathrm{m}$ TCT.

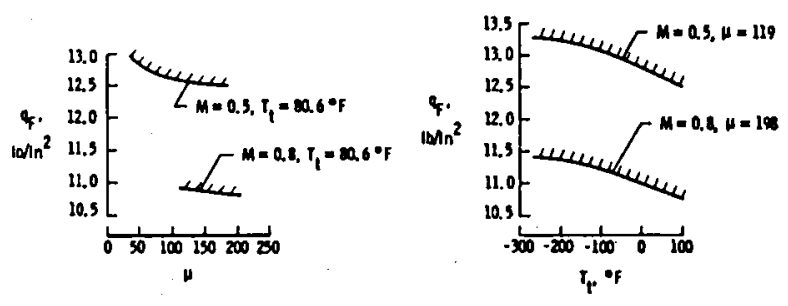

Fig. 15 Calculated mass ratio and temperature effects on flutter dynamic pressure.

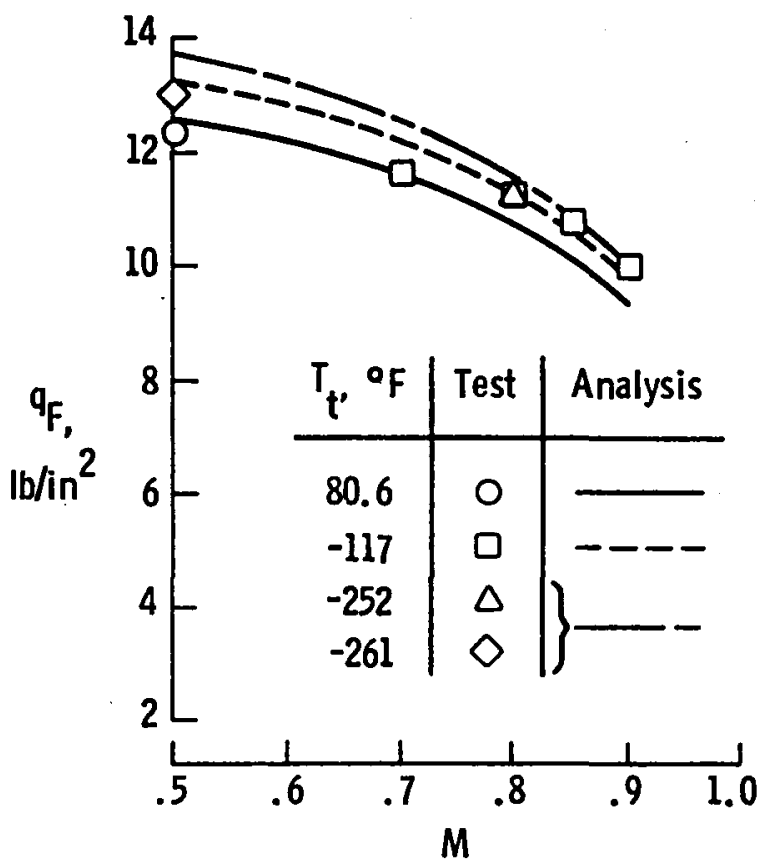

Fig. 16 Experimental and calculated flutter results.

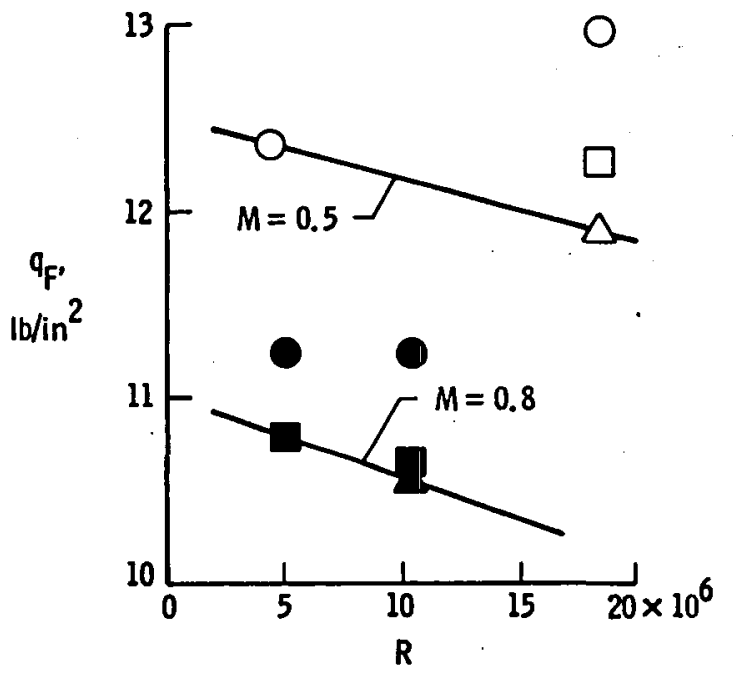

Fig. 17 Experimental effects of Reynolds number on $\mathrm{QF}$. 


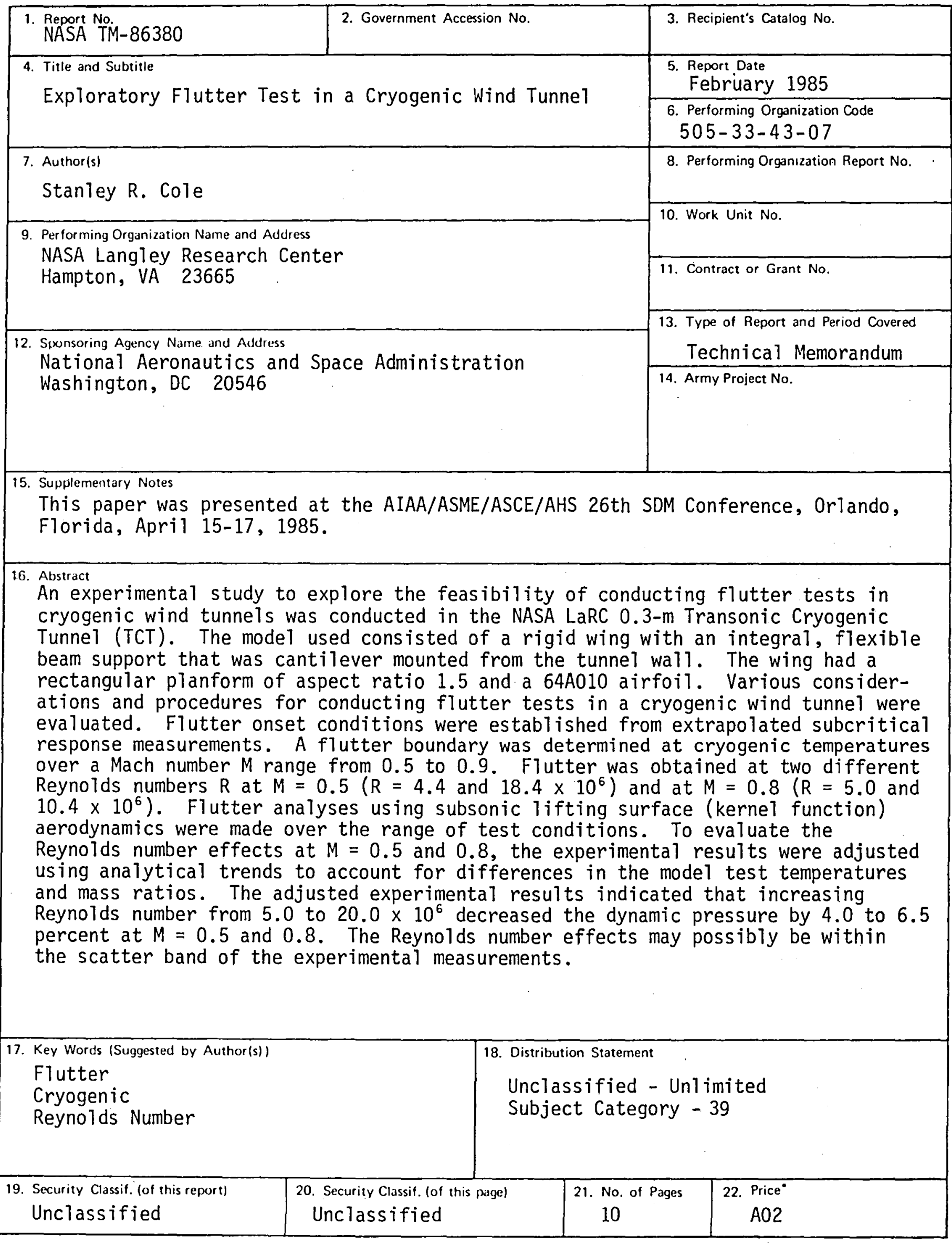


End of Document

, 